\title{
MODELO MATEMÁTICO DE PREVISÃO DE PROPRIEDADES MECÂNICAS NA ARCELORMITTAL CARIACICA*
}

Luciana Vilarinho Ramos de Carvalho ${ }^{1}$ Rosan Fernandes Lima² Marcelo Lucas Pereira Machado ${ }^{3}$

\section{Resumo}

O objetivo deste estudo foi desenvolver um modelo matemático capaz de prever as propriedades mecânicas de uma barra redonda laminada a quente em aço ao carbono, em termos de limite de escoamento e limite de resistência, considerando equações consagradas na literatura e dados industriais de processo. Foram utilizados os parâmetros de processo da laminação, tais como temperatura, deformação, taxa de deformação e tempo entre passes, e a composição química do aço SAE 1020. Os resultados calculados pelo modelo apresentaram boa concordância com os resultados medidos nas amostras, com diferença percentual de 3,34\% para limite de escoamento e 2,14\% para limite de resistência, além de mostrar-se adequado para previsão da evolução microestrutural, considerando as equações de recristalização estática e dinâmica. A utilização deste modelo pode levar à redução de custos com ensaios de tração e atender à demanda crescente dos clientes por estas informações nos certificados de qualidade.

Palavras-chave: Modelo Matemático; Barra Redonda; Propriedades Mecânicas.

\section{MATHEMATICAL MODEL TO PREDICT THE MECHANICAL PROPERTIES AT ARCELORMITTAL CARIACICA}

\begin{abstract}
The main subject of this study is to develop a mathematical model capable of predicting the mechanical properties of a hot rolled round bar carbon steel in terms of yield strength and tensile strength, considering equations published in literature and industrial process data. Rolling process parameters, such as temperature, strain, strain rate and interpass time as well as the SAE 1020 steel chemical composition were used. The results predicted by the model showed good agreement with the test results. The mean error was $3.34 \%$ for yield strength and $2.14 \%$ for tensile strength. The model also showed to be suitable for predicting grain size evolution, considering static and dynamic recrystallization. The use of this model can be lead to cost saving in tensile tests and can meet customer's demand for this type of information on quality certificates.
\end{abstract}

Keywords: Mathematical Model; Round Bars; Mechanical Properties.

1 Mestranda em Engenharia Metalúrgica e Materiais IFES, Engenheira de Processo e Produto, ArcelorMittal Cariacica, Cariacica, ES, Brasil.

2 Supervisor do Laboratório Físico e Metalográfico, ArcelorMittal Cariacica, Cariacica, ES, Brasil.

3 Engenheiro Metalurgista, Doutor, Professor Titular, IFES, Vitória, ES, Brasil.. 


\section{INTRODUÇÃO}

Desenvolvimentos de modelos matemáticos com o objetivo de simular a evolução microestrutural dos aços nos processos de conformação mecânica vêm sendo objetos de estudo por muitos autores há várias décadas e em diversos países do mundo. Existem modelos desenvolvidos para laminação a quente de chapas, barras, fio máquina, tiras e perfis. Estes modelos revelaram que é possível conhecer os eventos metalúrgicos e acompanhar a evolução microestrutural que ocorrem durante o processo de laminação em escala microscópica como uma função de mudanças de processo macroscópicas [1]. Logo, determinar variáveis, que não podem ou são extremamente difíceis de serem obtidas como tamanho de grão austenítico após um determinado passe de laminação se torna possível através do modelamento matemático, e consequentemente outras variáveis podem também ser estimadas, tais como a carga de laminação, o tamanho de grão ferrítico e as propriedades mecânicas do produto laminado.

Este trabalho apresenta o desenvolvimento de um modelo matemático aplicado na laminação de barras redondas de aço baixo carbono, cujo objetivo é prever as propriedades mecânicas em termos de Limite de Escoamento e Limite de Resistência, considerando equações consagradas na literatura e dados industriais de processo. A exigência dos clientes pelos resultados de propriedades mecânicas das barras redondas tem aumentado consideravelmente, devido à aplicação final desses materiais principalmente como parafusos, porcas, arruelas e tirantes. No entanto, as normas de barra redonda no estado laminado não especificam valores mínimos a serem atingidos por ensaio de tração. E, por este motivo não é procedimento padrão realizar este ensaio neste tipo de produto. Neste sentido, o uso do modelo matemático se torna uma ferramenta interessante para atender às necessidades dos clientes e por outro lado não onerar a usina com ensaios de tração.

\section{MATERIAIS E MÉTODOS}

Basicamente, o modelo é subdividido em três fases: modelo de evolução da austenita, modelo de transformação de fase e modelo de propriedades mecânicas, conforme mostrado na Figura 1. Na primeira etapa, de posse dos parâmetros de processo da laminação a quente e composição química do aço, é determinado o tipo de mecanismo de amaciamento (recristalização estática ou dinâmica) que ocorre no passe de laminação, onde são aplicadas as equações correspondentes ao tipo de recristalização, até a determinação do tamanho de grão austenítico final, ou seja, na saída do último passe. Em seguida, ocorre a etapa de transformação de fase durante o resfriamento, onde a austenita dará origem à ferrita e à perlita, como é o caso do aço C-Mn, e o modelo executa o cálculo do tamanho de grão ferrítico após completa transformação. Finalmente, de posse do tamanho de grão ferrítico e da composição química do aço, são realizados os cálculos das propriedades mecânicas finais do material, para os Limites de escoamento (LE) e de resistência (LR). 


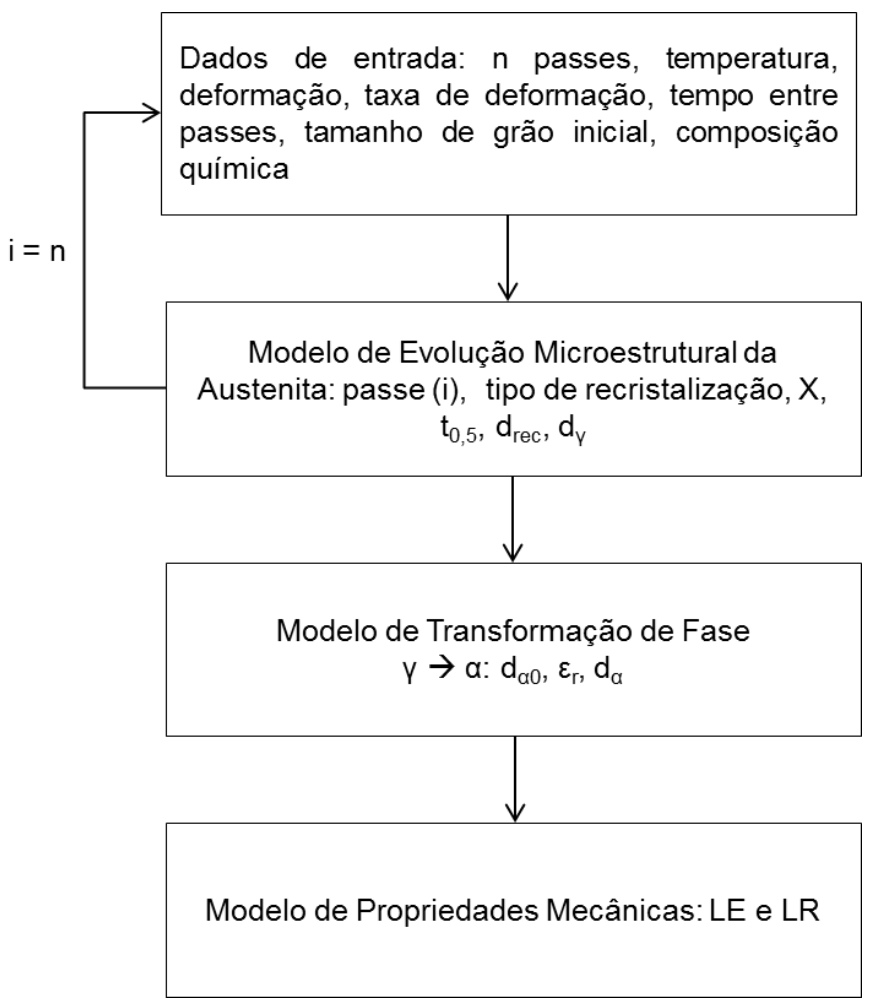

Figura 1. Fluxograma esquemático das etapas utilizadas na previsão das propriedades mecânicas finais dos produtos laminados a quente.

Para o desenvolvimento do modelo matemático foram utilizados os dados industriais da laminação a quente de Barra Redonda Mecânica (BRM) na bitola de 3/4" $(19,05 \mathrm{~mm})$ na Linha Leve da usina da ArcelorMittal Cariacica, como dados de entrada do modelo, bem como a composição química do aço SAE 1020, apresentados nas Tabelas 1 e 2 , respectivamente, .

Tabela 1. Parâmetros de processo (temperatura - $T$, taxa de deformação - $\dot{\varepsilon}$, deformação $\varepsilon$ e tempo entre passes - tep), na laminação a quente de BRM 3/4" SAE 1020

\begin{tabular}{ccccc}
\hline Passe & $\mathbf{T}\left(\mathbf{o}^{-} \mathbf{C}\right)$ & $\dot{\boldsymbol{\varepsilon}}\left(\mathbf{s}^{-1}\right)$ & $\boldsymbol{\varepsilon}$ & tep (s) \\
\hline 1 & 1061 & 9,48 & 0,21 & 5,5 \\
\hline 2 & 1059 & 11,16 & 0,28 & 4,6 \\
\hline 3 & 1057 & 9,27 & 0,21 & 2,0 \\
\hline 4 & 1056 & 13,18 & 0,32 & 5,2 \\
\hline 5 & 1054 & 15,65 & 0,46 & 10,0 \\
\hline 6 & 1048 & 3,50 & 0,42 & 3,3 \\
\hline 7 & 1045 & 5,02 & 0,46 & 2,0 \\
\hline 8 & 1044 & 13,22 & 0,63 & 1,1 \\
\hline 9 & 1043 & 13,22 & 0,55 & 3,8 \\
\hline 10 & 1039 & 24,92 & 0,55 & 2,5 \\
\hline 11 & 1031 & 25,72 & 0,52 & 12,1 \\
\hline 12 & 1015 & 47,98 & 0,56 & 0,9 \\
\hline 13 & 1014 & 53,24 & 0,56 & 0,8 \\
\hline 14 & 1012 & 97,38 & 0,54 & 0,6 \\
\hline 15 & 1011 & 91,94 & 0,53 & 30,5 \\
\hline Entrada leito & 949 & - & - & - \\
\hline Saída leito & 379 & - & - & - \\
\hline
\end{tabular}


Tabela 2. Composição química das corridas utilizadas no estudo e do aço SAE 1020 conforme norma SAE J403 (\% massa).

\begin{tabular}{ccccccccc}
\hline & $\mathbf{C}$ & $\mathbf{M n}$ & $\mathbf{S i}$ & $\mathbf{P}$ & $\mathbf{C u}$ & $\mathbf{N i}$ & $\mathbf{N}$ & $\mathbf{C e q}$ \\
\hline $\mathrm{A}$ & 0,21 & 0,57 & 0,16 & 0,020 & 0,21 & 0,04 & 0,0071 & 0,31 \\
\hline $\mathrm{B}$ & 0,19 & 0,57 & 0,14 & 0,021 & 0,24 & 0,05 & 0,0081 & 0,29 \\
\hline C & 0,20 & 0,56 & 0,13 & 0,022 & 0,21 & 0,05 & 0,0073 & 0,29 \\
\hline D & 0,21 & 0,57 & 0,14 & 0,019 & 0,20 & 0,05 & 0,0072 & 0,31 \\
\hline Mín. J403 & 0,18 & 0,30 & - & - & - & - & - & - \\
\hline Máx. J403 & 0,23 & 0,60 & - & 0,030 & - & - & - & - \\
\hline
\end{tabular}

A temperatura em cada passe foi calculada com base no modelo de Tiagunov [2] e validada através de medições de temperatura com câmera termográfica FLIR 650 (emissividade de 0,85).

O tamanho de grão austenítico inicial, ou seja, do na entrada do 1o passe de laminação, foi obtido através do aquecimento de duas amostras de tarugo do aço SAE 1020 no forno de mufla do Laboratório Físico da usina, a temperatura de $1095^{\circ} \mathrm{C}$, onde permaneceram por 30 minutos, simulando a condição real de encharque do tarugo no forno de reaquecimento da laminação. As amostras foram temperadas em água e em seguida foi realizado análise metalográfica.

Após o modelo determinar o tipo de recristalização gerado no passe, calcula-se 0 tempo para $50 \%$ de recristalização $\left(\mathbf{t}_{\mathbf{0}, 5}\right)$ e a fração recristalizada no passe $(X)$. Existem equações disponíveis na literatura para cálculo do tempo e da fração recristalizada, tanto estática quanto metadinâmica, para diferentes tipos de aços. No presente trabalho, por se tratar de um aço baixo carbono da classe SAE 1020, foram utilizadas as seguintes equações ajustadas por Maccagno et.al [3] para cada tipo de recristalização possível, conforme resumido na Tabela 3.

Tabela 3. Equações utilizadas no modelo de evolução microestrutural

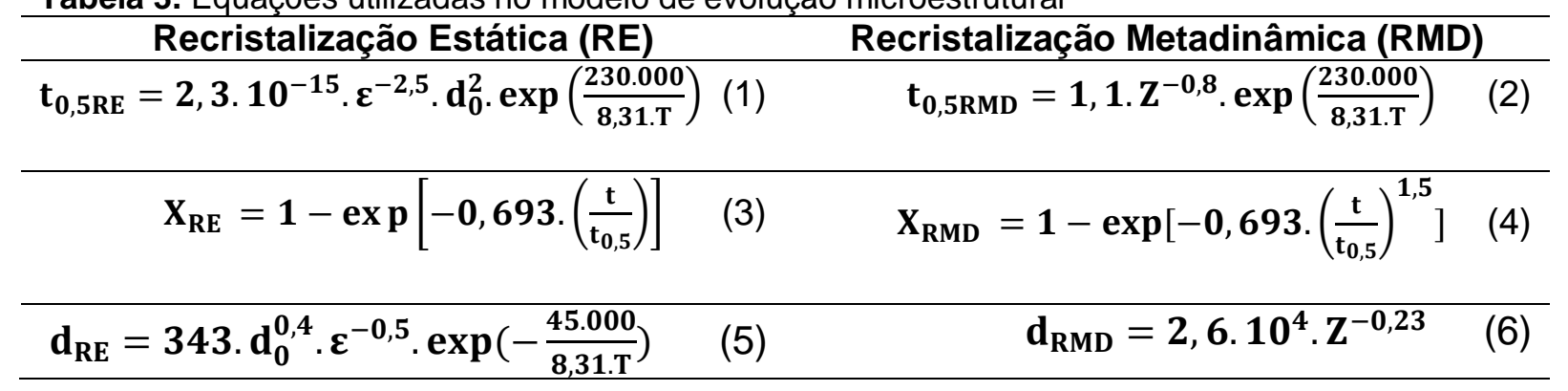

Ao se atingir $95 \%$ de recristalização no passe, considera-se que houve recristalização completa. A partir daí, tem-se início o processo de crescimento dos grãos, favorecido pelas altas temperaturas envolvidas na laminação a quente e o tempo entre passes ser geralmente muito maior que o tempo para a recristalização completa. O resultado é o tamanho de grão austenítico final (d) de um determinado passe, e que será considerado como o tamanho de grão inicial do passe seguinte, que pode ser calculado de acordo com as equações 7 a 10 [3]. 
- Tempos entre passes curtos $(\mathrm{t}<1 \mathrm{~s})[3]$ :

$$
\begin{gathered}
d^{2}=d_{\mathrm{RE}}^{2}+4,0 \cdot 10^{7} \cdot\left(t_{\mathrm{ep}}-4,32 \cdot t_{0,5}\right) \cdot \exp \left(-\frac{113.000}{8,31 \cdot \mathrm{T}}\right) \\
\text { ou } \\
d^{2}=d_{\mathrm{RMD}}^{2}+1,2 \cdot 10^{7} \cdot\left(t_{\mathrm{ep}}-2,65 \cdot t_{0,5}\right) \cdot \exp \left(-\frac{113.000}{8,31 \cdot \mathrm{T}}\right)
\end{gathered}
$$

- Tempos entre passes longos ( $t>1 \mathrm{~s})[3]$ :

$$
\begin{gathered}
d^{7}=d_{R E}^{7}+1,5 \cdot 10^{27} \cdot\left(t_{e p}-4,32 \cdot t_{0,5}\right) \cdot \exp \left(-\frac{400.000}{8,31 \cdot T}\right) \\
\text { ou } \\
d^{7}=d_{R M D}^{7}+8,2 \cdot 10^{25} \cdot\left(t_{e p}-2,65 \cdot t_{0,5}\right) \cdot \exp \left(-\frac{400.000}{8,31 \cdot T}\right)
\end{gathered}
$$

Caso não ocorra recristalização completa no passe, considera-se que não haverá crescimento de grão, e o tamanho de grão médio na entrada do passe seguinte pode ser calculado a partir de uma relação do tipo "lei das misturas", que leva em conta os grãos recristalizados e os não-recristalizados originados no passe anterior, conforme equação 11 [6]:

$$
d=X^{4 / 3} d_{r e c}+(1-X)^{2} d_{0}
$$

Onde drec é o tamanho de grão médio recristalizado no passe através de recristalização estática ou metadinâmica e do é o tamanho de grão na entrada do passe.

Além disso, a recristalização parcial gera um encruamento, e isto é medido pela

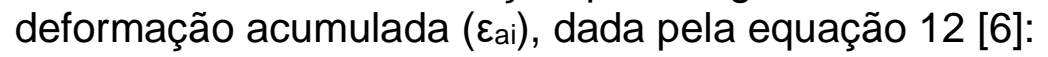

$$
\varepsilon_{a i}=\varepsilon_{i}+\left(1-X_{i-1}\right) \varepsilon_{a i-1}
$$

Para a definição do tipo de recristalização que ocorre no passe, é necessário calcular a deformação crítica, de acordo com a equação 13 para aço C-Mn [3]:

$$
\begin{array}{r}
\varepsilon_{c}=5,6 \times 10^{-4} \times d_{0}^{0,3} \times Z^{0,17} \\
Z=\dot{\varepsilon} \cdot \exp \left(\frac{300.000}{8,31 T}\right)
\end{array}
$$

Onde, do é o tamanho de grão austenítico no início do passe e $Z$ é o parâmetro Zener-Hollomon e T é a temperatura absoluta do material na entrada da cadeira de laminação (em K).

Se a deformação crítica $\left(\varepsilon_{c}\right)$ calculada for menor que a deformação acumulada no passe $\left(\varepsilon_{\mathrm{ai}}\right)$, tem-se que o mecanismo de amaciamento que ocorre no passe é a recristalização dinâmica, seguido de metadinâmica. Por outro lado, se a deformação crítica for maior, o mecanismo predominante é de recristalização estática.

Ao finalizar a sequência de passes, o material é transferido por meio de uma mesa de rolos até o leito de resfriamento, onde ao se resfriar lentamente ao ar, a estrutura se transforma de austenita para ferrita e perlita. O modelo sugerido no trabalho de 
Hodgson e Gibbs [1] considera somente a transformação de austenita em ferrita e perlita em microestruturas predominantemente ferríticas $(\mathrm{Ceq}<0,45)$, e desta forma se aplica a este estudo.

Em aços C-Mn, C-Mn-V e C-Mn-Ti há um efeito significativo da composição química no tamanho de grão ferrítico que deve ser levado em consideração para um bom modelamento. Segundo Hodgson e Gibbs [1] para aços cujo Ceq é menor que $0,35 \%$, o tamanho de grão ferrítico após transformação da austenita completamente recristalizada $\left(\mathbf{d}_{\mathbf{\alpha} 0}\right)$ é dado por:

$\mathbf{d}_{\alpha 0}=(-0,4+6,37$. Ceq $)+(24,2-59$. Ceq $) \cdot \dot{\mathbf{T}}^{-0,5}+22 .(1-\exp (-0,015 . \mathrm{d})$

Onde, $\mathrm{Ceq}=\mathrm{C}+\mathrm{Mn} / 6$

T é a taxa de resfriamento em ${ }^{\circ} \mathrm{C} / \mathrm{s}$

d é o tamanho de grão austenítico após último passe em $\mu \mathrm{m}$

Caso não haja recristalização completa após o último passe de laminação, haverá uma deformação residual na austenita $\left(\boldsymbol{\varepsilon}_{\mathbf{r}}\right)$, que leva em consideração apenas a fração não recristalizada do último passe. Isto consequentemente acarretará num refino do grão ferrítico na transformação de fase. O tamanho de grão ferrítico final $\left(\mathbf{d}_{\boldsymbol{\alpha}}\right)$ é calculado segundo equação 16 [1]:

$$
d_{\alpha}=d_{\alpha 0}\left(1-0,45 \cdot \sqrt{\varepsilon_{\mathrm{r}}}\right)
$$

Finalmente, é possível prever as propriedades mecânicas em termos de Limite de Escoamento (LE) e Limite de Resistência (LR) de acordo com as equações publicadas por Hodgson e Gibbs [1] para diferentes aços baixo carbono e microligados (Ceq < 0,35\%). Outros trabalhos publicados que consideraram estas equações também obtiveram excelentes concordâncias com os resultados práticos e medidos nas amostras, como por exemplo, no trabalho de Reis [4].

$$
\begin{array}{r}
\mathrm{LE}=62,6+26,1 .(\mathrm{Mn})+60,2 .(\mathrm{Si})+759 .(\mathrm{P})+212,9 .(\mathrm{Cu})+3286 .(\mathrm{N})+\sigma_{\mathrm{p}}+ \\
19,7 . \mathrm{d}_{\boldsymbol{\alpha}}^{-0,5} \\
(17) \\
\mathrm{LR}=164,9+634,7 .(\mathrm{C})+53,6 .(\mathrm{Mn})+99,7 .(\mathrm{Si})+651,9 .(\mathrm{P})+472,6 .(\mathrm{Ni})+ \\
3339,4 .(\mathrm{N})+\sigma_{\mathrm{p}}+11 . \mathrm{d}_{\boldsymbol{\alpha}}^{-0,5}
\end{array}
$$

Onde, $\boldsymbol{d}_{\boldsymbol{\alpha}}$ é o tamanho de grão ferrítico final

$\sigma_{p}$ é a contribuição do endurecimento por precipitação, que no caso de aço comum C-Mn foi considerado igual a zero.

Os resultados de LE e LR previstos pelo modelo matemático foram comparados com os resultados reais medidos nas amostras de barra redonda retiradas após a saída do leito de resfriamento. Ao todo foram retiradas 20 amostras, sendo 05 de cada corrida e realizados ensaios de tração no Laboratório Físico da usina. Também foram realizadas análises de tamanho de grão ferrítico nestas amostras e os resultados foram comparados aos previstos pelo modelo. A determinação do tamanho de grão ferrítico das amostras do produto laminado foi realizada de acordo com a norma ASTM E-112 (Método do intercepto). 


\section{RESULTADOS E DISCUSSÃO}

As equações 1 a 14 foram aplicadas na sequencia de 15 passes de laminação de tarugos na seção quadrada de $130 \times 130 \mathrm{~mm}$ até a bitola de barra redonda de 3/4" (19,05 mm) de diâmetro para a determinação do tamanho de grão austenítico final.

O tamanho de grão austenítico médio encontrado nas amostras de tarugo através dos ensaios de Laboratório foi de $87,5 \mu \mathrm{m}$, que é bem próximo do valor de $100 \mu \mathrm{m}$ adotado por alguns autores no modelamento de aços C-Mn [3,5]. As figuras $2 a$ e $2 b$ apresentam a mudança na estrutura interna do tarugo antes e após o reaquecimento no forno a temperatura de $1095^{\circ} \mathrm{C}$, onde se pode observar os contornos de grão. Este valor foi utilizado no modelo como tamanho de grão austenítico inicial, conforme apresentado na Tabela 4.

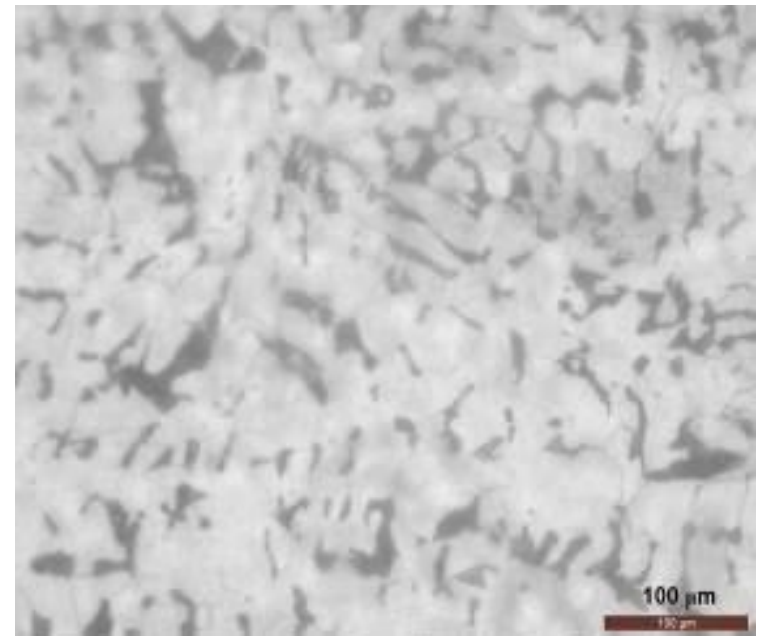

Figura 2a. Micrografia do tarugo antes do Ataque Teepol, 200x.

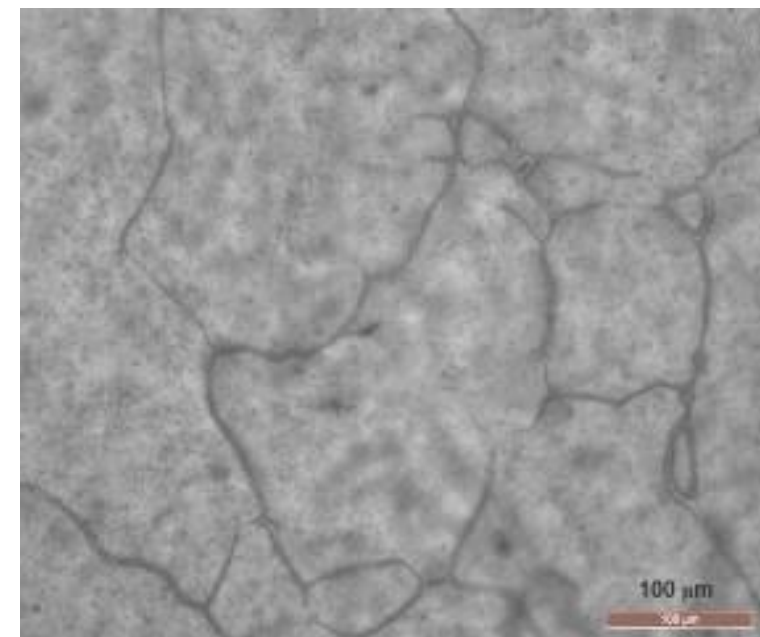

Figura 2b. Micrografia do tarugo após o reaquecimento no forno. Ataque Teepol, 200x.

A Tabela 4 apresenta a planilha de cálculo da evolução do tamanho de grão austenítico da BRM 3/4" SAE 1020.

Tabela 4. Evolução do tamanho de grão austenítico na laminação de BRM 3/4" SAE 1020.

\begin{tabular}{cccccccccccc} 
Passe & $\begin{array}{c}\boldsymbol{d}_{\mathbf{0}} \\
(\mu \mathrm{m})\end{array}$ & $\begin{array}{c}\mathrm{T} \\
\left({ }^{\circ} \mathrm{C}\right)\end{array}$ & $\begin{array}{c}\dot{\boldsymbol{\varepsilon}} \\
\left(\mathrm{s}^{-1}\right)\end{array}$ & $\begin{array}{c}\text { tep } \\
(\mathrm{s})\end{array}$ & $\boldsymbol{\varepsilon}$ & $\boldsymbol{\varepsilon}_{\boldsymbol{a}}$ & $\boldsymbol{\varepsilon}_{\boldsymbol{c}}$ & $\begin{array}{c}\text { Estática ou } \\
\text { Dinâmica? }\end{array}$ & $\begin{array}{c}\boldsymbol{t}_{\mathbf{0 , 5}} \\
(\mathrm{s})\end{array}$ & $\begin{array}{c}\mathrm{X} \\
(\%)\end{array}$ & $\begin{array}{c}\boldsymbol{d}_{\boldsymbol{\gamma}} \\
(\mu \mathrm{m})\end{array}$ \\
\hline 1 & 87,5 & 1061 & 9,48 & 5,5 & 0,21 & 0,21 & 0,31 & Estática & 0,92 & 1,00 & 78,0 \\
\hline 2 & 78,0 & 1059 & 11,16 & 4,6 & 0,28 & 0,29 & 0,31 & Estática & 0,34 & 1,00 & 64,8 \\
\hline 3 & 64,8 & 1057 & 9,27 & 2,0 & 0,21 & 0,21 & 0,29 & Estática & 0,53 & 0,93 & 61,7 \\
\hline 4 & 61,7 & 1056 & 13,18 & 5,2 & 0,32 & 0,34 & 0,30 & Dinâmica & 0,06 & 1,00 & 36,8 \\
\hline 5 & 36,8 & 1054 & 15,65 & 10,0 & 0,46 & 0,46 & 0,27 & Dinâmica & 0,05 & 1,00 & 39,5 \\
\hline 6 & 39,5 & 1048 & 3,50 & 3,3 & 0,42 & 0,42 & 0,22 & Dinâmica & 0,16 & 1,00 & 38,2 \\
\hline 7 & 38,2 & 1045 & 5,02 & 2,0 & 0,46 & 0,46 & 0,23 & Dinâmica & 0,12 & 1,00 & 34,8 \\
\hline 8 & 34,8 & 1044 & 13,22 & 1,1 & 0,63 & 0,63 & 0,27 & Dinâmica & 0,06 & 1,00 & 29,3 \\
\hline 9 & 29,3 & 1043 & 13,22 & 3,8 & 0,55 & 0,55 & 0,25 & Dinâmica & 0,06 & 1,00 & 33,5 \\
\hline
\end{tabular}




\begin{tabular}{llllllllllll}
\hline 10 & 33,5 & 1039 & 24,92 & 2,5 & 0,55 & 0,55 & 0,30 & Dinâmica & 0,03 & 1,00 & 30,7 \\
\hline 11 & 30,7 & 1031 & 25,72 & 12,1 & 0,52 & 0,52 & 0,30 & Dinâmica & 0,03 & 1,00 & 36,9 \\
\hline 12 & 36,9 & 1015 & 47,98 & 0,9 & 0,56 & 0,56 & 0,37 & Dinâmica & 0,02 & 1,00 & 23,7 \\
\hline 13 & 23,7 & 1014 & 53,24 & 0,8 & 0,56 & 0,56 & 0,34 & Dinâmica & 0,02 & 1,00 & 22,5 \\
\hline 14 & 22,5 & 1012 & 97,38 & 0,6 & 0,54 & 0,54 & 0,37 & Dinâmica & 0,01 & 1,00 & 19,2 \\
\hline 15 & 19,2 & 1011 & 91,94 & 30,5 & 0,53 & 0,53 & 0,35 & Dinâmica & 0,01 & 1,00 & 38,7 \\
\hline
\end{tabular}

Observa-se pelos cálculos que as deformações nos passes iniciais 1, 2 e 3 não foram suficientes para iniciar a recristalização dinâmica, pois a deformação crítica foi maior que a deformação acumulada, e, portanto, o mecanismo de amaciamento que se deu nos três passes foi estático. Nos passes 1 e 2, de acordo com os cálculos da cinética, houve tempo suficiente para completa recristalização estática $(X=1)$ seguida de crescimento de grão. Já no passe 3 , como a recristalização foi parcial $(X=0,93)$, não houve crescimento de grão. Com isso, parte da deformação acumulada do passe 3 somada ao aumento da taxa de deformação, levou a uma recristalização dinâmica no passe 4 . Nota-se também um intenso refino do grão austenítico do passe 4 oriundo da recristalização dinâmica.

A partir do passe 4, todo o mecanismo de amaciamento que ocorreu foi de recristalização dinâmica e metadinâmica seguido de crescimento de grão, uma vez que houve recristalização completa em todos os passes. Vale destacar que 0 tamanho de grão recristalizado metadinamicamente depende somente da taxa de deformação e da temperatura no passe, e por este motivo, o tamanho de grão ao final do passe é independente do tamanho de grão no início do passe [3]. $O$ crescimento de grão obtido no passe 5 pode ser explicado pelo longo tempo entre passes, conforme apresentado na tabela 4 . $O$ crescimento de grão significativo observado após o último passe de laminação se deve à distância entre a última cadeira de laminação e o leito de resfriamento.

Pela análise dos resultados do modelo de evolução da austenita apresentados na tabela 4 , observa-se que houve um refino de grão austenítico de $87,5 \mu \mathrm{m}$ para $38,7 \mu \mathrm{m}$.

Ao atingir o leito de resfriamento, a barra apresentou temperatura média de $929^{\circ} \mathrm{C}$ e após ser resfriada ao ar no leito de resfriamento por aproximadamente $420 \mathrm{~s}$, a temperatura média da barra na saída do leito estava em torno de 379ํㅡ. Portanto, a taxa média de resfriamento calculada foi de $1,36^{\circ} \mathrm{C} / \mathrm{s}$.

A Figura 3 mostra os resultados de tamanho de grão ferrítico final obtidos através do modelo matemático e os resultados médios encontrados em cada uma das amostras retiradas do produto laminado. 


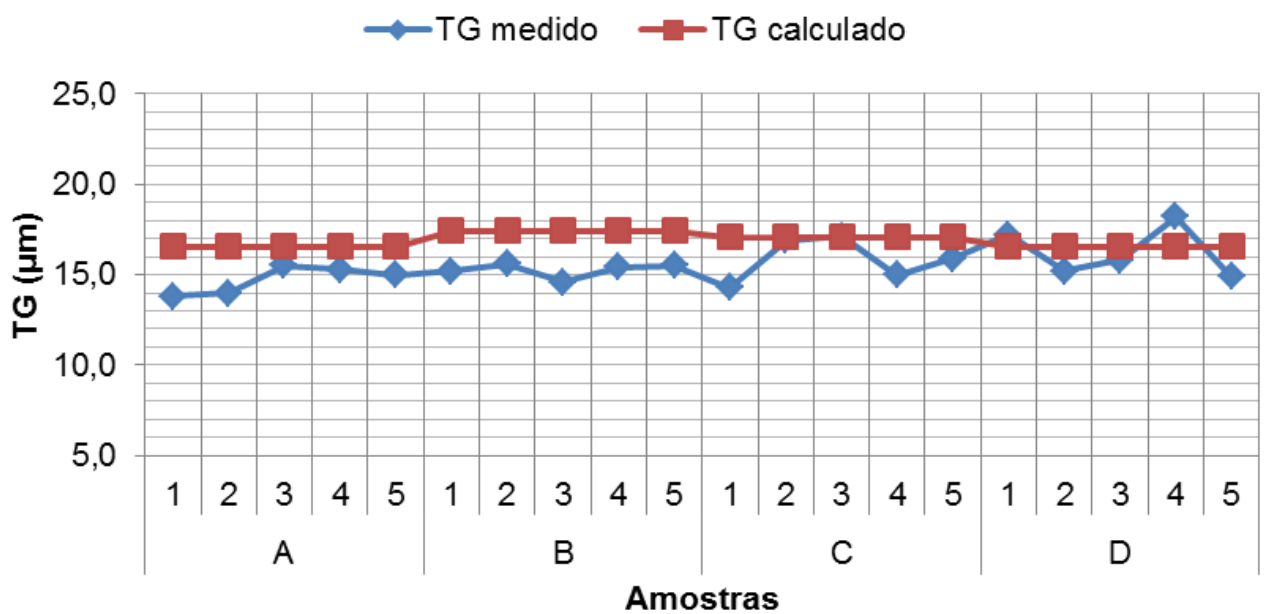

Figura 3. Resultados de Tamanho de Grão Ferrítico medidos nas amostras e calculados pelo modelo para cada corrida utilizada no estudo.

Os valores médios do tamanho grão ferrítico final calculado e medido foram de 16,9 e $15,5 \mu \mathrm{m}$, respectivamente, resultando em uma diferença percentual de $8,93 \%$.

A Figura 4 apresenta a microestrutura final do material laminado após resfriamento ao ar no leito. Os percentuais médios de ferrita e perlita medidos foram de $77 \%$ e $23 \%$, respectivamente, demonstrando uma predominância da fase ferrítica.
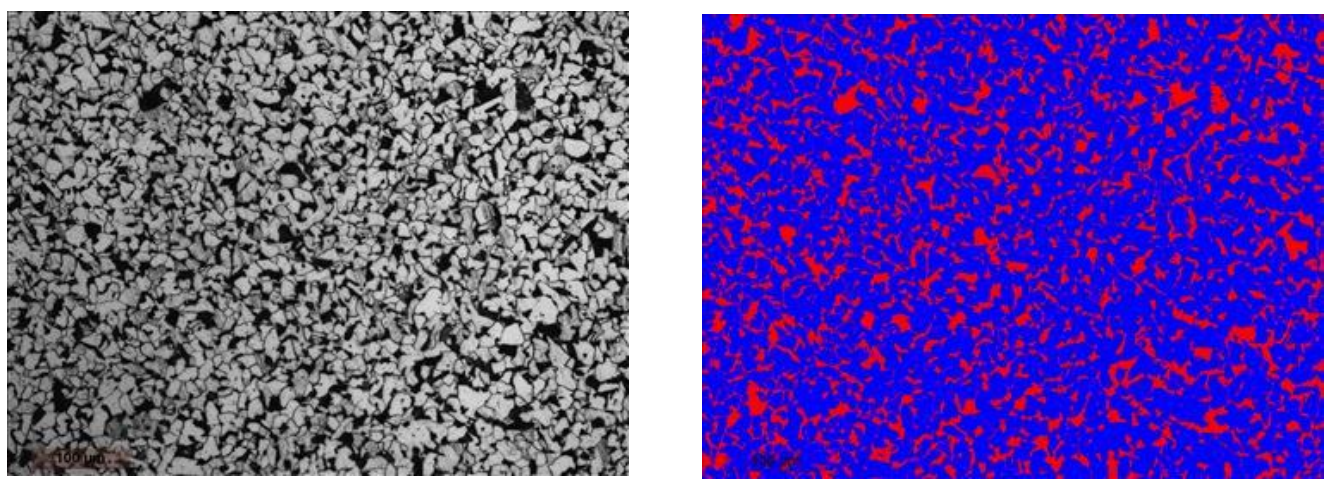

Figura 4. Microestrutura do aço SAE 1020 - BRM 3/4". Ataque nital 3\%, 100x. Imagem original (à esquerda) e imagem processada (à direita) pelo software Leica.

De acordo com Hodgson e Gibbs [1], a Figura 5 apresenta curvas onde se pode encontrar o tamanho de grão ferrítico em função do carbono equivalente para tamanhos de grão austenítico finais de 20 e $40 \mu \mathrm{m}$. Como o aço em estudo apresenta Ceq médio de $0,30 \%$ e o tamanho de grão austenítico final do modelo foi $38,7 \mu \mathrm{m}$, obtém-se da figura 5, o valor aproximado de $16 \mu \mathrm{m}$ para o tamanho de grão ferrítico do material. Isto está de acordo com o calculado pelo modelo que foi de 16,9 $\mu \mathrm{m}$, em média, conforme mostrado na figura 3 , e, portanto com uma diferença percentual de $5 \%$ em relação ao estudo de Hodgson e Gibbs, demonstrando uma boa previsibilidade do modelo para a evolução do tamanho de grão durante a laminação e após o resfriamento. 


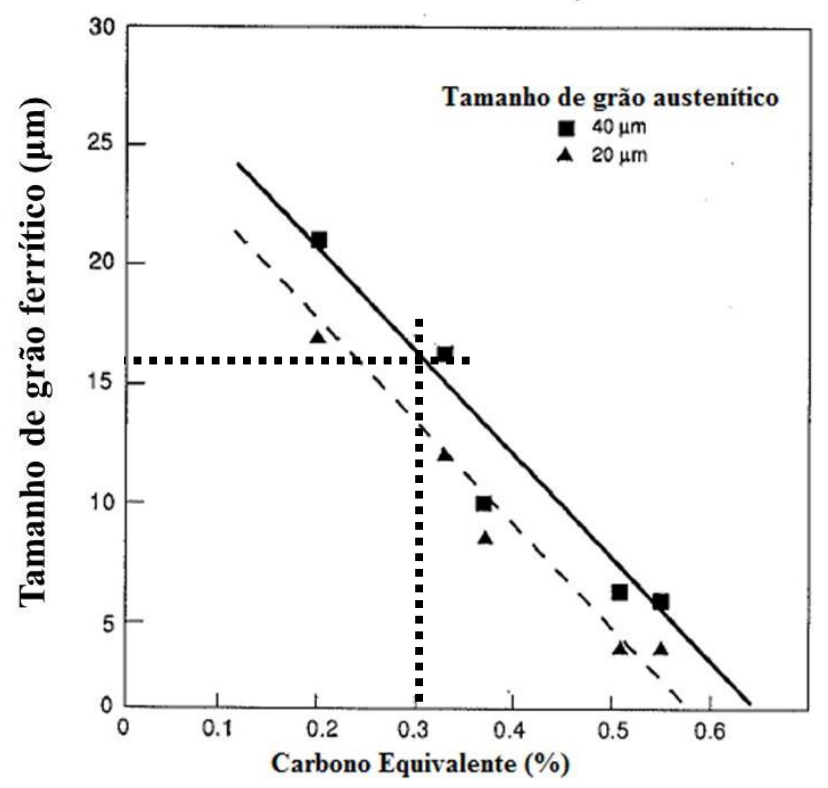

Figura 5. Variação do tamanho de grão ferrítico com o Ceq para aços C-Mn - Adaptado [1].

De posse da composição química e dos valores calculados do tamanho de grão ferrítico final de cada corrida, conforme as equações 17 e 18, foi possível realizar a previsão dos Limites de Escoamento (LE) e de Resistência (LR), respectivamente. As Figuras 6 e 7 apresentam uma comparação entre os resultados das propriedades mecânicas obtidos pelo modelo matemático e experimentalmente através do ensaio de tração das amostras.

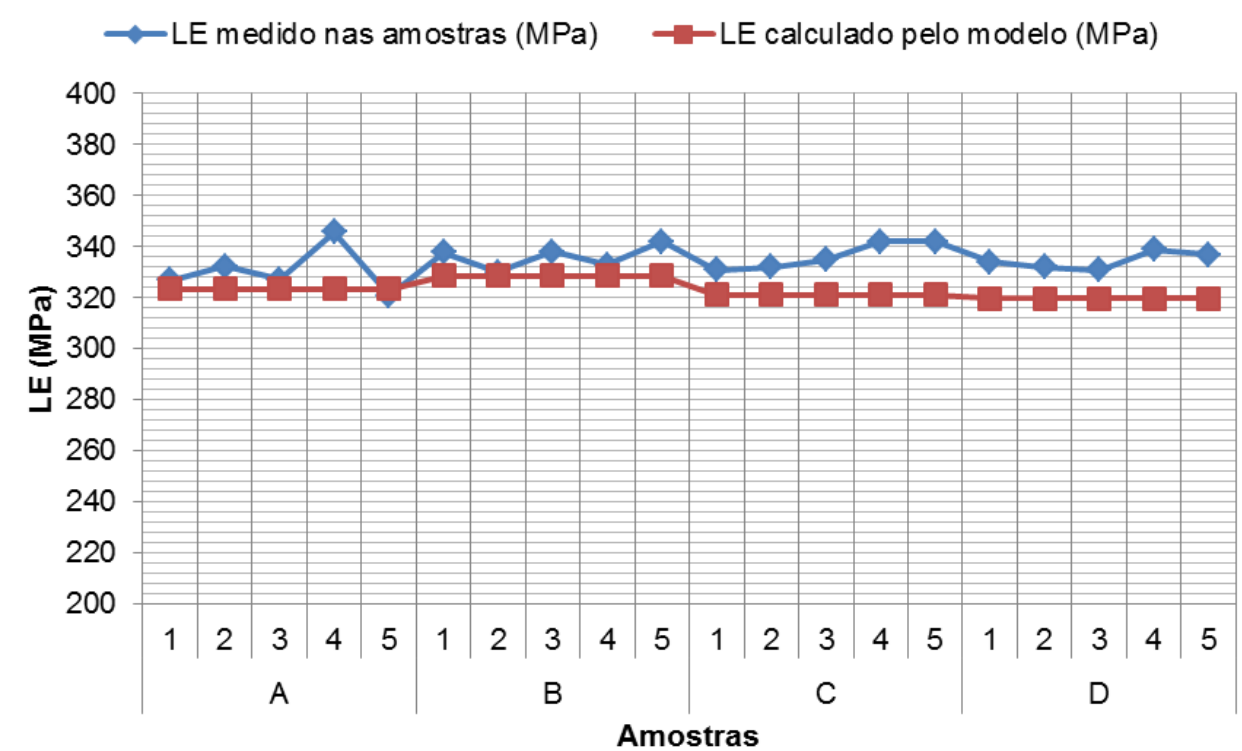

Figura 6. Resultados de LE (MPa) medido nas amostras e previsto pelo modelo. 


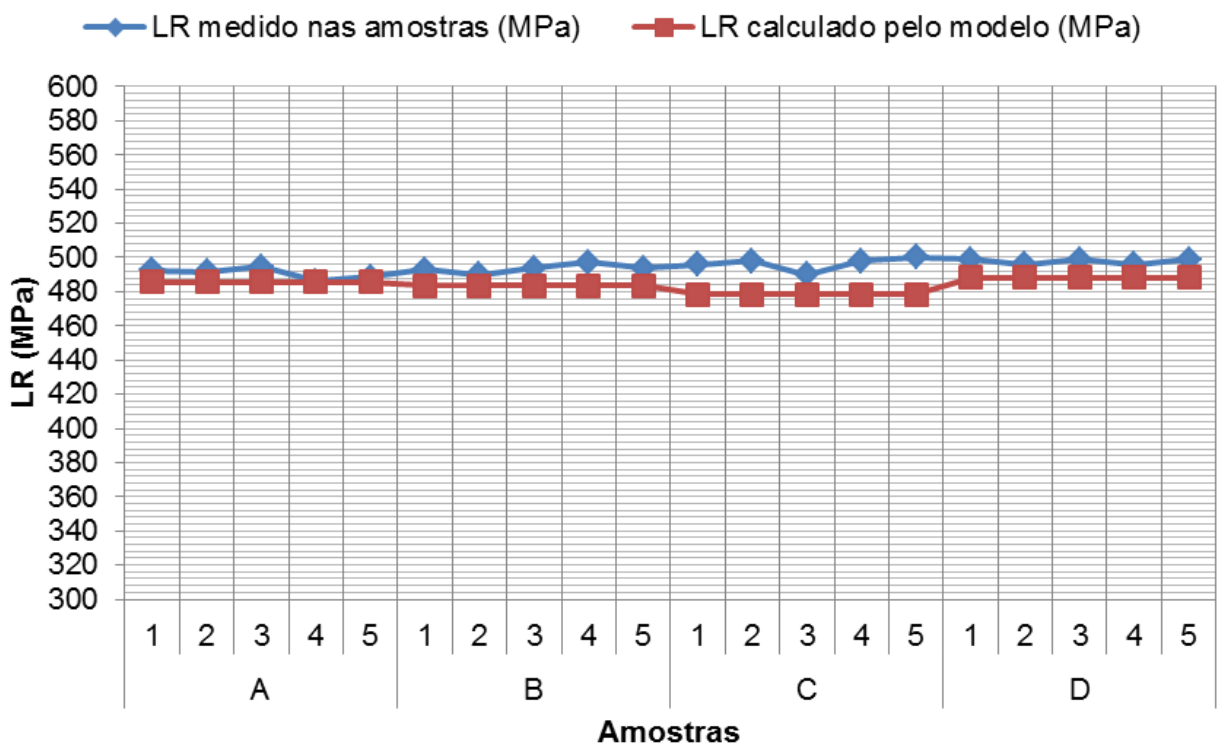

Figura 7. Resultados de LR (MPa) medido nas amostras e previsto pelo modelo.

Os resultados médios de LE do modelo e do ensaio foram de 323 e $334 \mathrm{MPa}$, respectivamente, acarretando uma diferença percentual de 3,34\%. E para o LR, os resultados médios entre o modelo e o ensaio foram de 484 e $495 \mathrm{MPa}$, respectivamente, levando a uma diferença percentual de $2,14 \%$.

\section{CONCLUSÃo}

O modelo de evolução microestrutural desenvolvido apresentou boa previsibilidade da evolução do tamanho de grão austenítico durante o processo de laminação a quente e do tamanho de grão ferrítico final após o resfriamento, levando em consideração os mecanismos de amaciamento envolvidos no processo.

O modelo matemático utilizado mostrou ser capaz de prever com boa precisão os valores de limite de escoamento e limite de resistência da barra redonda mecânica de $3 / 4 "(19,05 \mathrm{~mm})$ do aço SAE 1020 , com pequena diferença percentual entre os valores medidos nas amostras e os calculados pelo modelo.

A utilização da metodologia proposta no presente trabalho mostrou ser uma boa alternativa para a empresa na busca pela redução de custos, através da redução de amostragens e ensaios de laboratório, além do aumento da satisfação dos clientes.

Este modelo irá contribuir para o atendimento da crescente demanda dos clientes pelos resultados de propriedades mecânicas nos certificados de qualidade de barras redondas.

\section{Agradecimentos}

Os autores agradecem à ArcelorMittal Cariacica pela oportunidade de realizar este trabalho e pelo apoio da equipe da Laminação, do Laboratório e da Assistência Técnica. 


\section{REFERÊNCIAS}

1 Hodgson PD, Gibbs RK. A Mathematical Model to Predict the Mechanical Properties of Hot Rolled C-Mn and Microalloyed Steels. ISIJ International. 1992; 32(12):1329-1338.

2 Wusatowski Z. Fundamentals of Rolling. Londres: Pergamon Press; 1969.

3 Maccagno TM, Jonas JJ, Hodgson PD. Spreadsheet Modelling of Grain Size Evolution during Rod Rolling. ISIJ International. 1996; 36(6):720-728.

4 Reis EG. Modelo matemático para previsão das propriedades mecânicas na laminação a quente de perfis estruturais [dissertação de mestrado]. Belo Horizonte: Universidade Federal de Minas Gerais; 2007

5 Siciliano Jr F, Jonas JJ. Mathematical Modelling of the Hot Strip Rolling of Microalloyed $\mathrm{Nb}$, Multiply-Alloyed Cr-Mo, and Plain C-Mn Steels. Metallurgical and Materials Transactions. 2000; 31(A):511-530.

6 Beynon $\mathrm{JH}$, Sellars CM. Modelling Microstructure and Its Effects during Multipass Hot Rolling. ISIJ International. 1992; 32(3):359-367. 